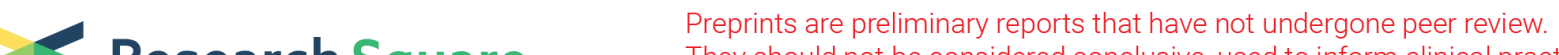 Research Square They should not be considered conclusive, used to inform clinical practice, or referenced by the media as validated information.
}

\section{A Comparative Study of Swine Tissue Composting With Woodchips, Rice Husk And Wheat Straw}

\author{
Zhenzhen Han \\ Huazhong Agricultural University \\ Xinyi Ruan \\ Huazhong Agricultural University \\ Xuchen Yang \\ Huazhong Agricultural University \\ Yajing Shan \\ Huazhong Agricultural University \\ Jin Chai \\ Huazhong Agricultural University \\ Rong Zheng ( $\nabla$ zhengrong@mail.hzau.edu.cn ) \\ Huazhong Agricultural University
}

\section{Research Article}

Keywords: Composting, Pig carcasses, Wheat straw, Bacterial community, diversity, nitrogen loss

Posted Date: June 21st, 2021

DOl: https://doi.org/10.21203/rs.3.rs-599429/v1

License: (c) (1) This work is licensed under a Creative Commons Attribution 4.0 International License.

Read Full License 


\section{Abstract}

This study evaluated the performance of woodchips (WS), rice husk (RH) and wheat straw (ST) in swine tissue composting. The ST treatment was shown to first reach the highest temperature $\left(55^{\circ} \mathrm{C}\right)$ at $12 \mathrm{~d}$ of composting and lasted 9 days. The total nitrogen content (TN) was higher and nitrogen loss was lower in ST than in WS or RH treatment. Ammonium nitrogen content(AN) analysis demonstrated lower $\mathrm{NH}_{3}$ emission in ST than in WS or RH treatment. Bacterial community analysis indicated that bacterial diversity was higher in ST than in WS or RH treatment. The most dominant genera in all composting treatments were Pseudomonas, Streptomyces, Brevibacterium, Saccharoporyspora, Acinetobacter, Sphingobacterium, Devosia, Rhizobium, Microbacterium and Sanguibacter. The dominant bacteria were Pseudomonas, Staphylococcus and Sphingobacterium in ST treatment, Streptomyces, Acinetobacter and Sphingopyxis in WS treatment, and Sanguibacter, Pedobacter and Gordonia in RH treatment. Spearman correlation analysis revealed positive relationship of Brevibacterium, Devosia, Sanguibacter, Brachybacterium and Promicromonospora to temperature; Brevibacterium and Staphylococcus to TN; Brevibacterium, Devosia, Microbacterium, Sanguibacter, Brachybacterium and Promicromonospora to AN. This research provides useful information for improving the efficiency of swine tissue composting.

\section{Introduction}

Aerobic composting can convert organic waste into a stabilized final product by microbial degradation, free of phytotoxicity and pathogens and with certain humic properties (Albrecht et al., 2010; Wei et al., 2014). Thus, it is considered as an environmentally friendly and economically viable alternative method for treating solid organic wastes, especially livestock and poultry manure (Zhang et al., 2019a). Animal carcasses are of high mass, high moisture content, high nitrogen content and zero porosity (Wilkinson, 2007), suggesting their difference from livestock and poultry manure in composting processes. Animal carcasses can not be mixed with materials evenly, which are usually placed in the center of the compost and covered with animal manure or some materials of good porosity, high carbon, low nitrogen(straw, corn silage or wood shavings) (Gilroyed et al., 2016). The composting of pig carcasses needs to undergo two processes: static stacking of carcass degradation and a maturation stage similar to the composting of livestock and poultry manure(Harper et al., 2009). By simulating field-scale livestock mortality composting systems, Akdeniz et al. (2010) designed a laboratory scale composting system with aerobic and anaerobic test units and tested the state and completion of the process by observing the gas concentrations of volatile organic compounds generated inside biosecure swine mortality composting units filled with six different materials. Glanville et al. (2016) assessed the potential of a passivelyventilated plastic-wrapped composting system for biosecure disposal of poultry mortalities caused by avian influenza as an emergency disposal option for disease-related swine mortalities. Ki et al. (2018) proposed a modified soil burial technique by covering swine carcasses to a final compost bed of 1.0-1.2 $\mathrm{m}$, with the temperature in the bed increasing gradually to $35-45^{\circ} \mathrm{C}$ after 200 days.

Numerous bulking agents, including woodchips, wheat straw, sawdust, rice husk, rice bran, chopped hay, wood shavings, and peanut shells, had been mixed with waste materials to adjust the moisture content, 
C/N ratio, and void spaces between particles (Adhikari et al., 2009; Gea et al., 2007; lqbal et al., 2010; Kim et al., 2008). These bulking agents have been reported to not only modify the physical properties of the composting feedstock, but also change the biodegradation kinetics and composting performance (Adhikari et al., 2008; Kim et al., 2008; Kulcu and Yaldiz, 2007; Yanez et al., 2009). Woodchips, rice husk and wheat straw are the most commonly used carbon sources owing to their less cost and recycling necessity. Woodchips might improve compost efficiency by increasing convective airflow through windrows to increase the supply of oxygen and enhance aerobic decomposition. Wheat straw has a high crystallinity and a high degree of polymerization (Snelders et al., 2014; Sun et al., 2014), whose degradability was retarded under natural conditions owing to chemical stability and high C: $\mathrm{N}$ ratio (Chen, 2014), but promoted in co-compost of cow manure (Awasthi et al., 2019). Rice husk acts as a sort of conditioner by providing structural support and exhibits best performance in reduction of antibiotic resistance genes (ARGs) in chicken manure and improving the efficiency of the treating process (Xiao et al., 2009; Zhang et al., 2019b).

Complex microbial communities play a key role in composting (Xi et al., 2015). Understanding the dynamic changes of microbial communities in the composting process is extremely important for efficient composting. In our previous work, Proteobacteria, Firmicutes, Bacteroidetes, and Actinobacteria were identified as the main phyla in the co-composting of wood shaving and swine carcasses (Yang et al., 2019). Proteobacteria, Firmicutes, Bacteroidetes, Actinobacteria, Acidobacter and Chloroflexi were determined as the dominant phyla in the co-composting of rice straw and cow manure (Sun et al., 2019). However, composting materials vary in their efficiency and microbial composition in the composting process. The purpose of this study was to compare the performance of woodchips, rice husk and wheat straw in the swine mortality composting process, determine the major microbial communities and their correlation to key environmental factors, and provide a theoretical basis for selecting effective carbon source materials to improve composting efficiency.

\section{Materials And Methods}

\subsection{Composting materials and experimental set-up}

The composting process was carried out from July 2, 2018 to April 25, 2018 at the pig breeding farm of Huazhong Agricultural University, Wuhan, Hubei province, China (30²8'28.96"N 114²0'12.24"E). The main materials for composting were woodchips, rice husk, wheat straw and swine carcasses. The woodchips, rice husk and wheat straw were collected from woodworking factories (Wuhan,China). Swine tissue were collected from the National Pig Breeding Center (Hongshan District, Wuhan, China). Every pile contained $20 \mathrm{~kg}$ carcass tissue (no internal organs). Before composting, wheat straw was shredded to a size of 20-30 mm by a fiber cutter SBJ-800F from Xinhang machinery Co.LTD (Qingzhou, China).

The prepared compost material base was placed in the center without overlapping, followed by addition of each compost material until reaching the initial dimensions of the whole pile ( $1.2 \mathrm{~m}$ long, $0.8 \mathrm{~m}$ wide and $0.5 \mathrm{~m}$ high). The initial moisture content was set at $60 \%$. A total of three treatment groups (WS, 
woodchips + swine carcasses; $\mathrm{RH}$, rice husk + swine carcasses; $\mathrm{ST}$, wheat straw + swine carcasses) were set up (length $0.1 \mathrm{~m}$, width $0.6 \mathrm{~m}$ and height $0.3 \mathrm{~m}$ ). Five-point sampling methods were used to collect subsamples at three different depths and five samples were obtained from each depth at day $0,6,12,21$, 30 ... 78. Then, the subsamples were mixed and divided into two portions, with one portion used for physical and chemical parameter determination and the other stored at $-20^{\circ} \mathrm{C}$ for further high-throughput sequencing analysis.

\subsection{Physical and chemical parameter analysis}

The temperature was measured by inserting an electronic thermometer into the core of the piles and thermometer is calibrated before use and the ambient temperature is measured. The temperature is measured once a day during mesophilic and thermophilic phase and once every 2-3 days during the cooling phases. The moisture content was determined by drying at $105^{\circ} \mathrm{C}$ for $24 \mathrm{~h}$. The pH value was determined in a 1:10 compost/water (w/v) suspension using a pH meter (FiveEasy Plus FE28, Mettler Toledo, Switzerland) after $1 \mathrm{~h}$ of equilibrium with shaking. The total nitrogen (TN) and total organic carbon (TC) was measured using an isotope ratio mass spectrometer (ISOPRIME 100, Elementar, Germany). The content of ammonium nitrogen (AN) was detected using a flow injection analyzer (Smartchem 200, AMS, Italy) (Supplementary table 1). Neutral detergent fiber (NDF), acid detergent fiber (ADF) and acid detergent lignin (ADL) were determined by using the British Ringbio filter bag technology fiber analyzer. Hemicellulose was estimated as the difference between NDF and ADF. Cellulose was estimated as the difference between ADF and ADL content. Lignin was estimated as the difference between $A D L$ and ash content.

\subsection{Illumina high-throughput sequencing data analysis}

The composting samples were subjected to DNA extraction using the MoBio PowerSoil $\circledast$ DNA Isolation Kit (12888). The V4 region of the 16S rRNA genes was amplified using the following primers: Forward 5'AYTGGGYDTAAAGNG-3' and Reverse 5'-TACNVGGGTATCTAATCC-3'. The PCR products were separated by $2.0 \%$ agarose gel electrophoresis and were purified with the Axygen Axy Prep DNA Gel Extration kit (AP-GX-500). After purification, the PCR products were quantified with Quant-iT PicoGreen dsDNA Assay Kit, Invitrogen (P7589) following the manufacturer's protocol. Next, the PCR products were pooled to construct amplicon libraries. The DNA library ( $\geq 2 \mathrm{nM}$ ) was diluted to $15-18 \mathrm{pM}$ and subjected to DNA sequencing on an Illumina MiSeq machine with $2 \times 300$ bp reads. Sequence quality was analyzed using the sliding window method to remove reads with an average Phred score lower than 20 or ambiguous bases or sequence length shorter than $150 \mathrm{bp}$ or mismatched primers. In addition, chimeras were removed with USEARCH using Qiime software. The obtained sequence fragments were assembled using the Flash software. Valid sequences were extracted according to the index information. The high-quality sequences were classified into operational taxonomic units (OTUs) with UCLUST using Qiime software at a 97\% similarity setting (Caporaso et al., 2010; Edgar, 2010). Finally, the taxonomic classification was performed using the Qiime pipeline.

Alpha diversity parameters, including Chao 1 estimator, ACE estimator, Shannon index, and Simpson index were measured for the five samples from each treatment using the Qiime software. Spearman 
correlation analysis was used to elucidate the relationship between the compost physiochemical properties and the patterns of bacterial community structure.

\subsection{Statistical analysis}

Spearman correlational analysis was performed using SPSS 20.0 (IBM Co., Armonk, NY, USA). Statistical calculations and data analysis were performed with the SPSS 22.0 statistical software package (IBM, USA) and GraphPad Prism version 7.0 for Windows (GraphPad Software, San Diego, CA, USA). A total of 5 replicates, 9 treatments. Results were presented as the mean \pm standard error from at least three independent experiments. P-values of $<0.05$ and $<0.01$ were considered as significant and highly significant, respectively.

\section{Results And Discussions}

\subsection{Comparison of temperature, moisture and $\mathrm{pH}$ of samples}

In Fig. 1, the pile temperature of wheat straw + swine tissues treatment (ST) rapidly increased and reached the thermophilic phase in the first 12 days of the process. The thermophilic phase was shorter in woodchips + swine carcass (WS) and rice husk + swine carcass (RH) treatments than in wheat straw + swine carcasses(ST) treatment. Moreover, the highest temperature in three composting treatments was in the order of $\mathrm{ST}\left(55^{\circ} \mathrm{C}\right)>\mathrm{WS}\left(42.6^{\circ} \mathrm{C}\right)>\mathrm{RH}\left(30.8^{\circ} \mathrm{C}\right)$. This might be due to the initial $\mathrm{C} / \mathrm{N}$ ratio of $\mathrm{ST}$ treatment (close to 30 ) (Table S1), which was determined as a better condition for reproduction of microorganisms (Hashemi and Han, 2019).

In Fig.2a, the sharpest decrease of moisture content among the three treatments was observed in the RH treatment in the first $30 \mathrm{~d}$ of composting, probably due to the compensation for the evaporation of moisture via the production of metabolic heat and water by biodegradation. After $30 \mathrm{~d}$, the moisture continued to decline in the ST treatment, probably due to its longer thermophilic stage, resulting in the greatest decreasing rate of moisture content among the three treatments. In Fig.2b, the pH value was shown to decrease rapidly in the $\mathrm{RH}$ treatment in the first $12 \mathrm{~d}$, probably due to the microbial activity on easily biodegradable organic matter and the release of organic acids in the materials (Robledo-Mahon et al., 2019; Tang et al., 2020; Lopez-Gonzalez et al., 2015). As composting progressed, the pH increased to around 7.0 at the end of the process, indicative of proper stabilisation of organic matter (Robledo-Mahon et al., 2019; Liu et al., 2018).

\subsection{Comparison of total organic carbon of samples}

The total organic carbon (TOC) was detected to decrease gradually during the composting process in all the three treatments. The initial TOCs of $48.84 \%, 41.75 \%$ and $38.69 \%$ decreased to $44.32 \%, 36.32 \%$ and $32.42 \%$ in the final composts of WS, RH and ST, respectively (Fig. 3). The TOC decrease percentage was in the order of ST $(15.9 \%)>\mathrm{RH}(12.99 \%)>$ WS $(9.32 \%)$. Compared with WS and RH, the ST feedstock exhibited slightly faster decomposition based on TOC reduction, probably attributed to more easily degradable organics contained in ST than in WS and RH (Qian et al., 2014).

3.3. Comparison of cellulose and lignin content of samples 
Figure 4 shows the cellulose and lignin contents of the three treatments throughout the 78-day natural composting period. In Fig. 4a, the final cellulose degradation rate was seen to be in the order of ST $(16.25 \%)>$ WS $(14.08 \%)>$ RH (13.01\%). In Fig. 4b, the final lignin degradation rate was shown to be ordered as ST $(45.05 \%)>\mathrm{RH}(25.33 \%)>\mathrm{WS}(0.79 \%)$. Both the lignin and cellulose degradation rates were significantly higher in ST than in WS or RH. A more favorable condition in ST may improve the microbial activity of cellulose-decomposing microorganisms (Sun et al., 2016; Yu et al., 2007; Zhao et al., 2016). The aforementioned results indicate that wheat straw could significantly promote lignocellulose degradation during swine tissue composting.

\subsection{Comparison of nitrogen profile of samples}

With the degradation of swine tissues, the total nitrogen content of the three groups all showed an upward trend (Fig. 5a). At the end of composting, the total nitrogen content of the straw group was the highest. It may be that straws have high nitrogen content and are rich in phosphorus, potassium, calcium, and magnesium, which are suitable for the growth of microorganisms and promote the degradation of organic matter

In Fig. 5b, the ammonium nitrogen (AN) content of ST and RH treatments showed a increase and reach a peak value, followed by a decrease throughout the composting process. Previous studies have indicated that the increase of ammonium nitrogen (AN) can be attributed to the mineralization and ammonification of organic nitrogen. up to 53d, the straw group had the highest ammonium nitrogen content among 3 groups, which further confirmed that the conversion efficiency of organic nitrogen was high and the composting process was good at the straw group. The ammonium nitrogen content of the woodchips group gradually increased, indicating that the composting process of the woodchips group was slow, but the woodchips has a larger void ratio, which can absorb $\mathrm{NH}_{4}{ }^{+}$(Hashemi et al., 2016), resulting in the highest final ammonium nitrogen content.

\subsection{Comparison of bacterial communities}

As shown in Table 1, the sequences of each sample were clustered as Operational Taxonomic Units (OTU) with over $97 \%$ identity. Among the three treatments, ST showed the highest OTU number in the samples at thermophilic stage, while the lowest OTU number in initial stage. In terms of Shannon index, ST showed a greater increase and decrease trend than WS or RH. The decrease of Shannon index from ST1 to ST2 might be due to the death of some species during the mesophilic phase, and the marked rise from ST2 (5.78) to ST3 (8.82) was related to the contribution of sufficient nutrients to the growth of some thermophilic or thermotolerant microorganisms (Sun et al., 2019) (Meng et al., 2019). The obvious drop of Shannon index after thermophilic phase was in line with the changes of Chao 1 index. In general, the highest diversity was shown by ST3 in the ST treatment, RH3 in the RH treatment, and WS4 in the WS treatment. 
Table 1

Effects of different treatments on Observed Sequences, OTU number, estimated indices (Simpson, Chao 1, ACE and Shannon) and coverage in five sampling stages.

\begin{tabular}{|c|c|c|c|c|c|c|}
\hline Sample & Sequence & OTUs & Simpson & Chao1 & ACE & Shannon \\
\hline WS1 & 45760 & 155 & 0.976902 & 1004.21 & 1046.8 & 7.47 \\
\hline WS2 & 44242 & 199 & 0.975829 & 1184.18 & 1236.44 & 7.49 \\
\hline WS3 & 31531 & 178 & 0.990941 & 2024.78 & 1970.42 & 8.84 \\
\hline WS4 & 34659 & 262 & 0.99608 & 2591.25 & 2602.74 & 9.52 \\
\hline WS5 & 34223 & 218 & 0.991009 & 2181.46 & 2333.1 & 9.15 \\
\hline $\mathrm{RH} 1$ & 38100 & 153 & 0.970149 & 967.56 & 1018.12 & 7.01 \\
\hline $\mathrm{RH} 2$ & 30279 & 193 & 0.979968 & 1302.64 & 1397.27 & 7.62 \\
\hline $\mathrm{RH} 3$ & 31768 & 247 & 0.992569 & 1953.25 & 2061.54 & 9.15 \\
\hline $\mathrm{RH} 4$ & 28314 & 206 & 0.968353 & 1325.03 & 1327.73 & 8.02 \\
\hline RH5 & 36626 & 234 & 0.991915 & 1942.27 & 1911.68 & 8.78 \\
\hline ST1 & 30948 & 169 & 0.968464 & 1125.01 & 1211.52 & 7 \\
\hline ST2 & 34252 & 173 & 0.93199 & 711.65 & 741.55 & 5.78 \\
\hline ST3 & 50685 & 399 & 0.990531 & 1979.12 & 2081.65 & 8.82 \\
\hline ST4 & 34685 & 266 & 0.989882 & 1712.15 & 1682.66 & 8.46 \\
\hline ST5 & 32329 & 194 & 0.991996 & 1345.6 & 1360.71 & 8.67 \\
\hline \multicolumn{7}{|c|}{$\begin{array}{l}\text { Note: Chao1 richness estimation index (Chao1) indicates the number of species in the community; the } \\
\text { ACE richness estimation index (ACE), the number of species in the community; Shannon diversity } \\
\text { index (Shannon), the richness and evenness of the community; Simpson diversity index (Simpson), } \\
\text { community diversity. The first column in the table is the sample name, followed by indexes of } \\
\text { Observed Sequences, OTU number, Chao1, ACE, Shannon, and Simpson coupled with the results of } \\
\text { samples in the same sequencing depth. } 1,2,3,4,5 \text { represent samples at five different periods, } \\
\text { including the initial phase, the warming phase, the high temperature phase, the cooling phase, and the } \\
\text { maturity phase. WS = woodchips + swine carcasses; RH = rice husk + swine carcasses; ST = wheat } \\
\text { straw + swine carcasses. }\end{array}$} \\
\hline
\end{tabular}

\subsection{Comparison of bacterial community composition at phylum and genus level}

Figure 6 presents the classification of 16S rRNA gene sequences at the phylum and genus level. For all the samples at the phylum level (Fig. 6a), the most dominant phyla included Proteobacteria,

Actinobacteria, Bacteroidetes, Firmicutes, Cyanobacteria, Chloroflexi, accounting for over $99 \%$ of the total $16 S$ rRNA gene sequences in each sample. The first four dominant taxonomic phyla were also found in composting of other wastes (Antunes et al., 2016; de Gannes et al., 2013; Wei et al., 2018). 
Proteobacteria was incredibly diverse and contained members of great importance to carbon, sulfur, and nitrogen cycles of the planet (Wei et al., 2018; Zhong et al., 2018; Yang et al., 2019). The abundance of Proteobacteria showed a downward trend in WS and RH treatments, but a trend of first rise and then fall in the ST treatment at the thermophilic phase, possibly due to the great importance of Proteobacteria phylum to global C, $\mathrm{N}$ and $\mathrm{S}$ cycling (Burges et al., 2020).

Actinobacteria plays a important role in degradation of refractory cellulose and lignin (Partanen et al., 2010; Peters et al., 2000; Su et al., 2015). Bacteroidetes plays a major role in organic matter degradation and $\mathrm{C}$ cycling (Wang et al., 2018); Bacteroidetes could break down lignocellulose into short chain fatty acids (Dodd et al., 2011; Zhong et al., 2018). Firmicutes is thought to play a major role in lignocellulose degradation (Pankratov et al., 2011). The relative abundance of Bacteroidetes and Firmicutes was both higher in ST than in WS or $\mathrm{RH}$, implying more rapid degradation of cellulose and lignin in ST (Fig. 4a-b). Cyanobacteria is the main $\mathrm{N}_{2}$ fixing organism in freshwater ecosystems (Li et al., 2019). Cyanobacteria showed higher abundance in ST than in WS or $\mathrm{RH}$, providing support for $\mathrm{N}$ pollution control, remediation, and management. Chloroflexi contains aerobic and anaerobic thermophiles, filamentous anoxygenic phototrophs, and anaerobic organohalide respirers (Maymo-Gatell et al., 1997; Xu et al., 2019). Chloroflexi exhibited the highest relative abundance in ST5 among all the samples, promoting rapid biodegradation of organic substances and then humification. Planctomycetes is considered as slow-growing decomposers of organic matter and has a unique anaerobic ammonium oxidation trait (Kulichevskaya et al., 2012; Zhong et al., 2018). Planctomycetes had the highest abundance in WS5 among all the samples, and this phylum may contribute to net nitrification in the compost piles.

Figure $6 \mathrm{~b}$ shows the top 20 genera in the composting samples. Among them, Pseudomonas, Brevundimonas, Acinetobacter, Devosia and Rhizobium belong to Proteobacteria. Streptomyces, Brevibacterium, Saccharoporyspora, Microbacterium, Sanguibacter and Brachybacteriumd belong to Actinobacteria. Sphingobacterium belongs to Bacteroidetes. Pseudomonas is widely distributed in nature and can decompose complex polymers such as lignocellulose (de Gannes et al., 2013). The relative abundance of Pseudomonas was higher in ST than WS or RH, probably due to its longer thermophilic phase and higher degradation rate of lignocellulose than either of them. Streptomyces and Acinetobacter began to emerge at the initial phase of WS treatment and reached the highest level at maturity phase. Streptomyces was a dominant bacterium during composting of swine carcasses and woodchips (Yang et al., 2019), which was related to the consumption and assimilation of ammonia (Kim et al., 2013; Yang et al., 2019). A comparison of these three treatments revealed the highest relative abundance of Brevibacterium in $\mathrm{RH} 3$ sample, which was consistent with the rise of total nitrogen content at the high temperature perid. Brevibacterium was related with total nitrogen and ammonium nitrogen content in swine carcass composting (Yang et al., 2019). Overall, the total abundance of the top 20 dominant genera was the higher in ST than in WS or $\mathrm{RH}$, indicating that the wheat straw treatment environment is more suitable for microbial growth. The dominant bacteria were Pseudomonas, Staphylococcus and Sphingobacterium in ST treatment, Streptomyces Acinetobacter and Sphingopyxis in WS treatment, and Sanguibacter, Pedobacter and Gordonia in RH treatment. 
3.7. Correlation analysis between bacterial communities and selected factors

Environmental factors are the main drivers for the development of microbial communities (Maeda et al., 2010). The potential effects of various physicochemical parameters ( $\mathrm{pH}, \mathrm{AN}, \mathrm{MC}$, temperature, TC, TN, cellulose, hemicellulose and lignin) on the bacterial community structure throughout the composting process were evaluated by Spearman analysis of the relationship between environmental factors and top 20 genera (Fig. 7). The variables of AN, MC, TN, hemicellulose and lignin and composting temperature were shown to have different (positive/negative) impacts on bacterial communities. Pseudomonas was positively related to $\mathrm{MC}$ and hemicellulose, but negatively related to temperature and AN. Brevibacterium was positively related to temperature, TN and AN. Saccharoporyspora showed a negative correlation with temperature. Brevundimonas showed a significant and positive correlation with $\mathrm{pH}$ and cellulose. Devosia showed a positive correlation with AN and temperature. Those observations corroborated our analysis results of physicochemical parameters. In terms of compost product, Pseudomonas, Brevibacterium, Devosia, Staphylococcus, Microbacterium, Sanguibacter, Brachybavterium and Promicromonospora all showed a positive correlation with $\mathrm{N}$ content, suggesting the high quality of the compost product. Among them, Brevibacterium, Devosia, Sanguibacter, Brachybavterium and Promicromonospora all showed a positive correlation with temperature, suggesting the high maturity of the compost product.

\section{Conclusion}

In this study, the environment of ST treatment is more suitable for microbial growth and swine tissue composting efficiency is higher than WS or RH treatments. The dominant bacteria were Pseudomonas, Staphylococcus and Sphingobacterium in ST treatment, Streptomyces Acinetobacter and Sphingopyxis in WS treatment, and Sanguibacter, Pedobacter and Gordonia in RH treatment. Spearman analysis revealed that bacterial species compositions in different composting materials were all significantly influenced by temperature, TN, MC, cellulose, lignin and AN. Pseudomonas, Brevibacterium, Devosia, Staphylococcus, Microbacterium, Sanguibacter, Brachybavterium and Promicromonospora all showed a positive correlation with N content. Among them, Brevibacterium, Devosia, Sanguibacter, Brachybavterium and Promicromonospora all exhibited a positive correlation with temperature, implying that the compost product has high security. The environmental factors vary in their effect on each species, and microbial communities can be effectively regulated by adjusting relevant environmental parameters. This research facilitates our understanding of the influence mechanism of woodchips, rice husk and wheat straw on the efficiency of swine tissue composting and contributes to the develop of high efficient microbial agent.

\section{Declarations}

\section{Data availability}

The datasets used and/or analyzed during the current study are available from the corresponding author on reasonable request.

\section{Acknowledgments}


We thank Jinlong Zhang at the pig breeding farm of HuaZhong Agricultural University for his support during the composting process.

\section{Funding}

This work was supported by National Key Research and Development Program of China [2017YFD0400300] and Hubei Province Major Technology Innovation Program of China [2017ABA137].

\section{Author information}

Affiliations

College of Animal Science and Technology, Huazhong Agricultural University, Wuhan, Hubei 430070, China

Zhenzhen Han, Xinyi Ruan, Xuchen Yang, Yajing Shan, Jin Chai, Rong Zheng

\section{Contributions}

Zhenzhen Han, Xinyi Ruan and Rong Zheng designed the study. Zhenzhen Han and Xinyi Ruan completed the entire experimental study. Zhenzhen Han and Xinyi Ruan wrote the manuscript with inputs from Rong Zheng and Jin Chai . Xuchen Yang and Yajing Shan helped with the statistical analysis, and the figures.

\section{Corresponding author}

Correspondence to Rong Zheng

\section{Ethics declarations}

\section{Competing Interest}

The authors declare that they have no known competing financial interests or personal relationships that could have appeared to influence the work reported in this paper.

\section{Ethics approval and consent to participate}

Not applicable.

\section{Consent for publication}

Not applicable.

\section{References}


1. Adhikari, B.K., Barrington, S., Martinez, J., King, S(2008)Characterization of food waste and bulking agents for composting. Waste Manage. 28, 795-804. https://doi.org/10.1016/ j.wasman.2007.08.018

2. Adhikari, B.K., Barrington, S., Martinez, J., King, S(2009)Effectiveness of three bulking agents for food waste composting. Waste Manage. 29, 197-203. https://doi.org/ 10.1016/j.wasman.2008.04.001

3. Akdeniz, N., Koziel, J.A., Ahn, H.K., Glanville, T.D., Crawford, B.P(2010)Field scale evaluation of volatile organic compound production inside biosecure swine mortality composts. Waste Manage. 30, 1981-1988. https://doi.org/10.1016/j.wasman.2010.05.022

4. Albrecht, R., Le Petit, J., Calvert, V., Terrom, G., Perissol, C(2010)Changes in the level of alkaline and acid phosphatase activities during green wastes and sewage sludge co-composting. Bioresource Technol. 101, 228-233. https://doi.org/10.1016/j.biortech.2009.08.017

5. Allen F, Harper., Mark J, Estienne(2009)Composting for Mortality Disposal on Hog Farms. VCE Publications / 414 / 414-020.

6. Antunes, L.P., Martins, L.F., Pereira, R.V., Thomas, A.M., Barbosa, D., Lemos, L.N., Silva, G.M., Moura, L.M., Epamino, G.W., Digiampietri, L.A., Lombardi, K.C., Ramos, P.L., Quaggio, R.B., de Oliveira, J.C., Pascon, R.C., Cruz, J.B., da Silva, A.M., Setubal, J.C(2016)Microbial community structure and dynamics in thermophilic composting viewed through metagenomics and metatranscriptomics. Sci. Rep-UK 6, 38915. https://doi.org/10.1038/srep38915

7. Awasthi, M.K., Duan, Y., Awasthi, S.K., Liu, T., Zhang, Z(2019)Effect of biochar and bacterial inoculum additions on cow dung composting. Bioresource Technol. 122407. https://doi.org/10.1016/j.biortech.2019.122407

8. Burges, A., Fievet, V., Oustriere, N., Epelde, L., Garbisu, C., Becerril, J.M., Mench, M(2020)Long-term phytomanagement with compost and a sunflower-Tobacco rotation influences the structural microbial diversity of a Cu-contaminated soil. Sci. Total Environ. 700, 134529. https://doi.org/10.1016/j.scitotenv.2019.134529

9. Caporaso, J.G., Kuczynski, J., Stombaugh, J., Bittinger, K., Bushman, F.D., Costello, E.K., Fierer, N., Pena, A.G., Goodrich, J.K., Gordon, J.I., Huttley, G.A., Kelley, S.T., Knights, D., Koenig, J.E., Ley, R.E., Lozupone, C.A., McDonald, D., Muegge, B.D., Pirrung, M., Reeder, J., Sevinsky, J.R., Turnbaugh, P.J., Walters, W.A., Widmann, J., Yatsunenko, T., Zaneveld, J., Knight, R(2010)QIIME allows analysis of high-throughput community sequencing data. Nat. Methods. 7, 335-336.

https://doi.org/10.1038/nmeth.f.303

10. De Gannes, V., Eudoxie, G., Hickey, W.J(2013) Prokaryotic successions and diversity in composts as revealed by 454-pyrosequencing. Bioresource Technol. 133, 573-580. https://doi.org/ 10.1016/j.biortech.2013.01.138

11. Dodd, D., Mackie, R.I., Cann, I.K(2011)Xylan degradation, a metabolic property shared by rumen and human colonic Bacteroidetes. Mol. Microbiol. 79, 292-304. https://doi.org/ 10.1111/j.13652958.2010.07473.x 
12. Edgar, R.C(2010)Search and clustering orders of magnitude faster than BLAST. Bioinformatics 26, 2460-2461. https://doi.org/ 10.1093/bioinformatics/btq461

13. Gea, T., Barrena, R., Artola, A., Sanchez, A(2007)Optimal bulking agent particle size and usage for heat retention and disinfection in domestic wastewater sludge composting. Waste Manage. 27, 1108-1116. https://doi.org/ 10.1016/j.wasman.2006.07.005

14. Gilroyed BH., Conrad C., Hao X., McAllister TA., Stanford K., Reuter T(2016)Composting for Biocontained Cattle Mortality Disposal and Associated Greenhouse Gas and Leachate Emissions. J Environ Qual. 45, 646-56. https://doi.org/10.2134/jeq2015.06.0314.

15. Glanville, T.D., Ahn, H., Akdeniz, N., Crawford, B.P., Koziel, J.A(2016)Performance of a plastic-wrapped composting system for biosecure emergency disposal of disease-related swine mortalities. Waste Manage. 48, 483-491. https://doi.org/ 10.1016/j.wasman.2015.11.006

16. Hashemi, S., Han, M(2019)Field evaluation of the fertilizing potential of biologically treated sanitation products. Sci. Total Environ. 650, 1591-1598. https://doi.org/

10.1016/j.scitotenv.2018.09.009

17. Hashemi, S., Han, M., Kim, T(2016)Optimization of fertilization characteristics of urine by addition of Nitrosomonas europaea bio-seed. J. Neurol. Sci. 96, 4416-4422. https://doi.org/ 10.1002/jsfa.7652

18. Iqbal, M.K., Shafiq, T., Ahmed, K(2010)Characterization of bulking agents and its effects on physical properties of compost. Bioresource Technol. 101, 1913-1919. https://doi.org/ 10.1016/j.biortech.2009.10.030

19. Ki, B.M., Kim, Y.M., Jeon, J.M., Ryu, H.W., Cho, K.S(2018)Characterization of odor emissions and microbial community structure during degradation of pig carcasses using the soil burial-composting method. Waste Manage. 77, 30-42. https://doi.org/ 10.1016/j.wasman.2018.04.043

20. Kim, J., Srinivasan, S., You, T., Bang, J.J., Park, S., Lee, S.S(2013)Brevibacterium ammoniilyticum sp. nov., an ammonia-degrading bacterium isolated from sludge of a wastewater treatment plant. Int. J. Syst. Evol. Micr. 63, 1111-1118. https://doi.org/ 10.1099/ijs.0.039305-0

21. Kim, K.Y., Kim, H.W., Han, S.K., Hwang, E.J., Lee, C.Y., Shin, H.S(2008)Effect of granular porous media on the composting of swine manure. Waste Manage. 28, 2336-2343. https://doi.org/ 10.1016/j.wasman.2007.10.015

22. Kulcu, R., Yaldiz, O(2007)Composting of goat manure and wheat straw using pine cones as a bulking agent. Bioresource Technol. 98, 2700-2704. https://doi.org/ 10.1016/j.biortech.2006.09.025

23. Kulichevskaya, I.S., Serkebaeva, Y.M., Kim, Y., Rijpstra, W.I., Damste, J.S., Liesack, W., Dedysh, S.N(2012) Telmatocola sphagniphila gen. nov., sp. nov., a novel dendriform planctomycete from northern wetlands. Front. Microbiol. 3, 146. https://doi.org/ 10.3389/fmicb.2012.00146

24. Li, Y., Wang, D., Chen, S., Yu, Z., Liu, L., Wang, M., Chen, Z(2019)N2 fixation in urbanization area rivers: spatial-temporal variations and influencing factors. Environ. Sci. Pollut R. 1-11. https://doi.org/ 10.1007/s11356-019-06780-w

25. Liu, L., Wang, S., Guo, X., Zhao, T., Zhang, B(2018)Succession and diversity of microorganisms and their association with physicochemical properties during green waste thermophilic composting. 
Waste Manage. 73, 101-112. https://doi.org/ 10.1016/j.wasman.2017.12.026

26. Lopez-Gonzalez, J.A., Suarez-Estrella, F., Vargas-Garcia, M.C., Lopez, M.J., Jurado, M.M., Moreno, $J(2015)$ Dynamics of bacterial microbiota during lignocellulosic waste composting: Studies upon its structure, functionality and biodiversity. Bioresource Technol. 175, 406-416. https://doi.org/ 10.1016/j.biortech.2014.10.123

27. Maeda, K., Hanajima, D., Morioka, R., Osada, T(2010)Characterization and spatial distribution of bacterial communities within passively aerated cattle manure composting piles. Bioresource Technol. 101, 9631-9637. https://doi.org/ 10.1016/j.biortech.2010.07.057

28. Maymo-Gatell, X., Chien, Y., Gossett, J.M., Zinder, S.H(1997)Isolation of a bacterium that reductively dechlorinates tetrachloroethene to ethene. Sci. 276, 1568-1571. https://doi.org/ $10.1126 /$ science. 276.5318 .1568

29. Meng, Q., Xu, X., Zhang, W., Men, M., Xu, B., Deng, L., Bello, A., Jiang, X., Sheng, S., Wu, $X(2019)$ Bacterial community succession in dairy manure composting with a static composting technique. Can. J. Microbiol. 65, 436-449. https://doi.org/ 10.1139/cjm-2018-0560

30. Pankratov, T.A., Ivanova, A.O., Dedysh, S.N., Liesack, W(2011)Bacterial populations and environmental factors controlling cellulose degradation in an acidic Sphagnum peat. Environ. Microbiol. 13, 1800-1814. https://doi.org/ 10.1111/j.1462-2920.2011.02491.x

31. Partanen, P., Hultman, J., Paulin, L., Auvinen, P., Romantschuk, M(2010)Bacterial diversity at different stages of the composting process. Bmc Microbiol. 10, 94. https://doi.org/ 10.1186/1471-2180-10-94

32. Peters, S., Koschinsky, S., Schwieger, F., Tebbe, C.C(2000)Succession of microbial communities during hot composting as detected by PCR-single-strand-conformation polymorphism-based genetic profiles of small-subunit rRNA genes. Appl. Environ. Microbiol. 66, 930-936. https://doi.org/ 10.1128/aem.66.3.930-936.2000

33. Qian, X., Shen, G., Wang, Z., Guo, C., Liu, Y., Lei, Z., Zhang, Z(2014)Co-composting of livestock manure with rice straw: characterization and establishment of maturity evaluation system. Waste Manage. 34, 530-535. https://doi.org/ 10.1016/j.wasman.2013.10.007

34. Robledo-Mahon, T., Martin, M.A., Gutierrez, M.C., Toledo, M., Gonzalez, I., Aranda, E., Chica, A.F., Calvo, C(2019)Sewage sludge composting under semi-permeable film at full-scale: Evaluation of odour emissions and relationships between microbiological activities and physico-chemical variables. Environ. Res. 177, 108624. https://doi.org/ 10.1016/j.envres.2019.108624

35. Schwarzlose, I., Gerdes, U., Gerlach, G. F., Runge, M., Thalmann, G., Nockler, A., Klarmann, D., Behr, K. P., Neumann, U., Seedorf, J., Hartung, J., \& Jeske, C(2008) Composting of poultry carcasses as an alternative method for disposal in case of an outbreak of an epizootic disease: first results. Dtsch Tierarztl Wochenschr. 115, 150-7.

36. Snelders, J., Dornez, E., Benjelloun-Mlayah, B., Huijgen, W.J., de Wild, P.J., Gosselink, R.J., Gerritsma, J., Courtin, C.M(2014)Biorefining of wheat straw using an acetic and formic acid based organosolv fractionation process. Bioresource Technol. 156, 275-282. https://doi.org/ 10.1016/j.biortech.2014.01.069 
37. Su, J.Q., Wei, B., Ou-Yang, W.Y., Huang, F.Y., Zhao, Y., Xu, H.J., Zhu, Y.G(2015)Antibiotic resistome and its association with bacterial communities during sewage sludge composting. Environ. Sci. Technol. 49, 7356-7363. https://doi.org/ 10.1021/acs.est.5b01012

38. Sun, L., Liu, T., Muller, B., Schnurer, A(2016)The microbial community structure in industrial biogas plants influences the degradation rate of straw and cellulose in batch tests. Biotechnol. Biofuels. 9, 128. https://doi.org/ 10.1186/s13068-016-0543-9

39. Sun, X.P., Lu, P., Jiang, T., Schuchardt, F., Li, G.X(2014)Influence of bulking agents on $\mathrm{CH}(4), \mathrm{N}(2) \mathrm{O}$, and $\mathrm{NH}(3)$ emissions during rapid composting of pig manure from the Chinese Ganqinfen system. J. Zhejiang Univ. Sci. B 15, 353-364. https://doi.org/ 10.1631/jzus.B13a0271

40. Tang, J., Zhang, L., Zhang, J., Ren, L., Zhou, Y., Zheng, Y., Luo, L., Yang, Y., Huang, H., Chen, A(2020) Physicochemical features, metal availability and enzyme activity in heavy metal-polluted soil remediated by biochar and compost. Sci. Total Environ. 701, 134751. https://doi.org/ 10.1016/j.scitotenv.2019.134751

41. Wang, K., Mao, H., Li, X(2018)Functional characteristics and influence factors of microbial community in sewage sludge composting with inorganic bulking agent. Bioresource Technol. 249, 527-535. https://doi.org/ 10.1016/j.biortech.2017.10.034

42. Wei, H., Wang, L., Hassan, M., Xie, B(2018)Succession of the functional microbial communities and the metabolic functions in maize straw composting process. Bioresource Technol. 256, 333-341. https://doi.org/ 10.1016/j.biortech.2018.02.050

43. Wei, Z., Zhang, X., Wei, Y., Wen, X., Shi, J., Wu, J., Zhao, Y., Xi, B(2014)Fractions and biodegradability of dissolved organic matter derived from different composts. Bioresource Technol. 161, 179-185. https://doi.org/ 10.1016/j.biortech.2014.03.032

44. Wilkinson, K.G(2007)The biosecurity of on-farm mortality composting. J. Appl. Microbiol. 102, 609618. https://doi.org/10.1111/j.1365-2672.2006.03274.x

45. Xi, B., He, X., Dang, Q., Yang, T., Li, M., Wang, X., Li, D., Tang, J(2015)Effect of multi-stage inoculation on the bacterial and fungal community structure during organic municipal solid wastes composting. Bioresource Technol. 196, 399-405. https://doi.org/10.1016/j.biortech.2015.07.069

46. Xiao, Y., Zeng, G.M., Yang, Z.H., Shi, W.J., Huang, C., Fan, C.Z., Xu, Z.Y(2009)Continuous thermophilic composting (CTC) for rapid biodegradation and maturation of organic municipal solid waste. Bioresource Technol. 100, 4807-4813. https://doi.org/10.1016/j.biortech.2009.05.013

47. Xu, Z., Li, G., Huda, N., Zhang, B., Wang, M., Luo, W(2019)Effects of moisture and carbon/nitrogen ratio on gaseous emissions and maturity during direct composting of cornstalks used for filtration of anaerobically digested manure centrate. Bioresource Technol. 298, 122503. https://doi.org/ 10.1016/j.biortech.2019.122503

48. Yanez, R., Alonso, J.L., Diaz, M.J(2009)Influence of bulking agent on sewage sludge composting process. Bioresource Technol. 100, 5827-5833. https://doi.org/10.1016/j.biortech.2019.122165

49. Yang, X.C., Han, Z.Z., Ruan, X.Y., Chai, J., Jiang, S.W., Zheng, R(2019)Composting swine carcasses with nitrogen transformation microbial strains: Succession of microbial community and nitrogen 
functional genes. Sci. Total Environ. 688, 555-566. https://doi.org/10.1016/j.scitotenv.2019.06.283

50. Yu, H., Zeng, G., Huang, H., Xi, X., Wang, R., Huang, D., Huang, G., Li, J(2007)Microbial community succession and lignocellulose degradation during agricultural waste composting. Biodegradation 18, 793-802. https://doi.org/10.1007/s10532-007-9108-8

51. Zhang, J., Bao, Y., Jiang, Y., Liu, H.T., Xi, B.D., Wang, D.Q(2019)Removal and dissipation pathway of typical fluoroquinolones in sewage sludge during aerobic composting. Waste Manage. 95, 450-457. https://doi.org/10.1016/j.wasman.2019.06.036

52. Zhang, J., Lin, H., Ma, J., Sun, W., Yang, Y., Zhang, X(2019)Compost-bulking agents reduce the reservoir of antibiotics and antibiotic resistance genes in manures by modifying bacterial microbiota. Sci. Total Environ. 649, 396-404. https://doi.org/ 10.1016/j.scitotenv.2018.08.212

53. Zhao, Y., Lu, Q., Wei, Y., Cui, H., Zhang, X., Wang, X., Shan, S., Wei, Z(2016)Effect of actinobacteria agent inoculation methods on cellulose degradation during composting based on redundancy analysis. Bioresource Technol. 219, 196-203. https://doi.org/10.1016/j.biortech.2016.07.117

54. Zhong, X.Z., Ma, S.C., Wang, S.P., Wang, T.T., Sun, Z.Y., Tang, Y.Q., Deng, Y., Kida, K(2018)A comparative study of composting the solid fraction of dairy manure with or without bulking material: Performance and microbial community dynamics. Bioresource Technol. 247, 443-452. https://doi.org/ 10.1016/j.biortech.2017.09.116

\section{Figures}

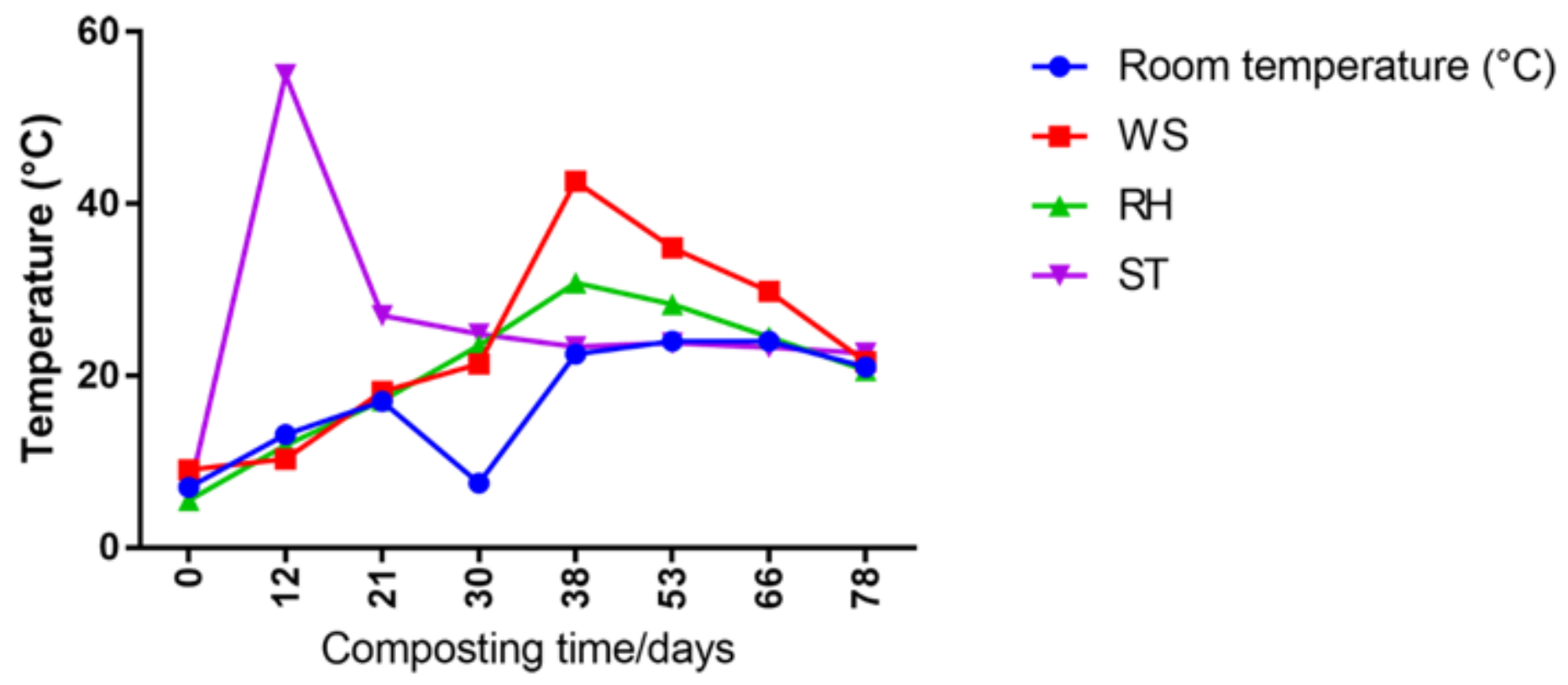

\section{Figure 1}

Temperature variations in WS, $\mathrm{RH}$ and ST during the composting process. WS = woodchips + swine carcasses; $\mathrm{RH}$ = rice husk + swine carcasses; $\mathrm{ST}$ = wheat straw + swine carcasses 
2a

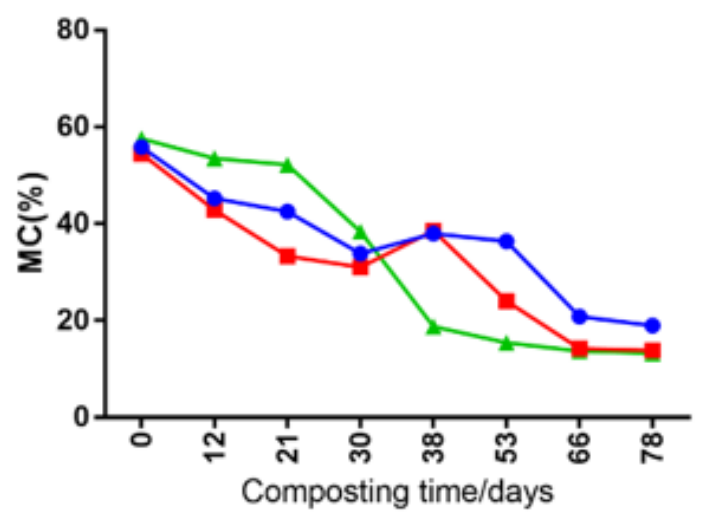

2b
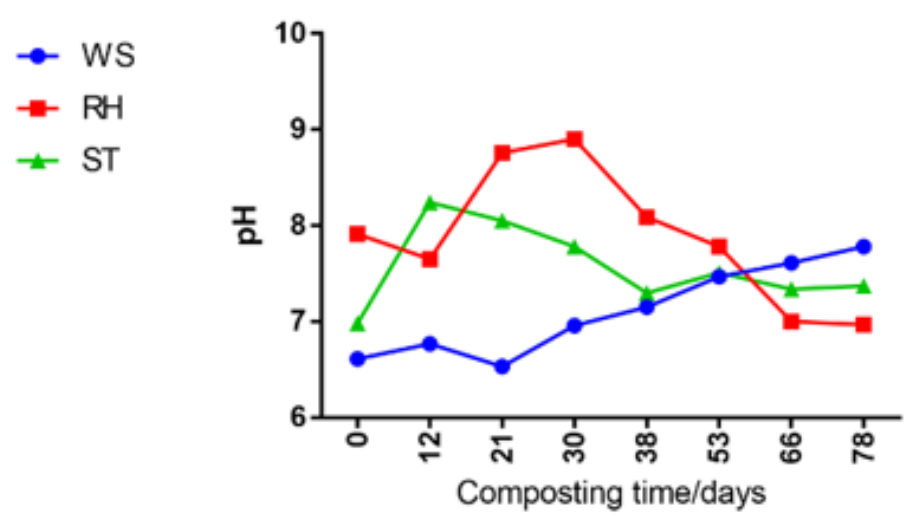

Figure 2

WS, RH and ST during composting process: (a) moisture content and (b) pH. WS = woodchips + swine carcasses; $\mathrm{RH}$ = rice husk + swine carcasses; $\mathrm{ST}$ = wheat straw + swine carcasses.

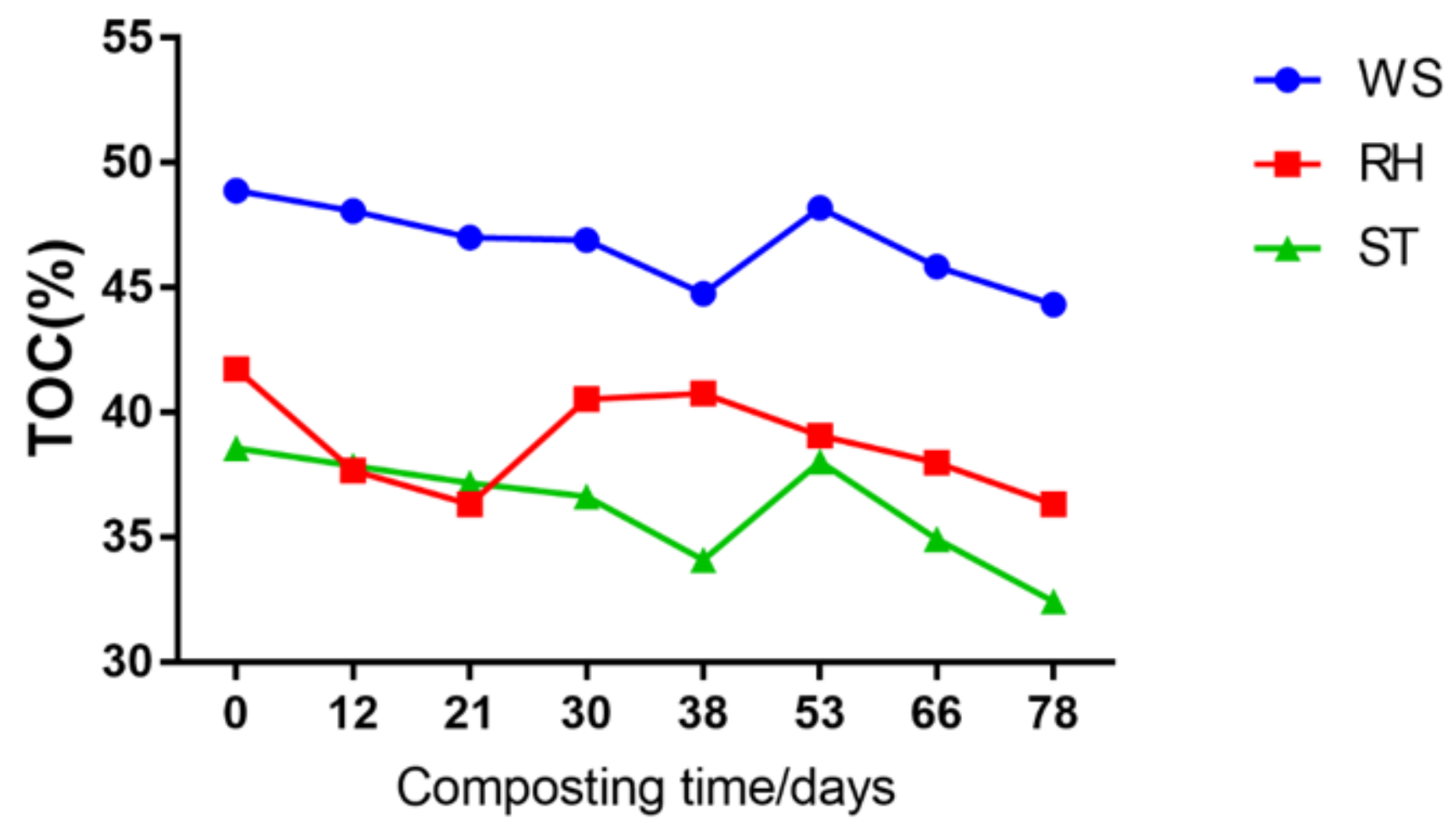

Figure 3

The content of total organic carbon during composting process. WS = woodchips + swine carcasses; $\mathrm{RH}=$ rice husk +swine carcasses; $\mathrm{ST}=$ wheat straw + swine carcasses. 


\section{$4 a$}

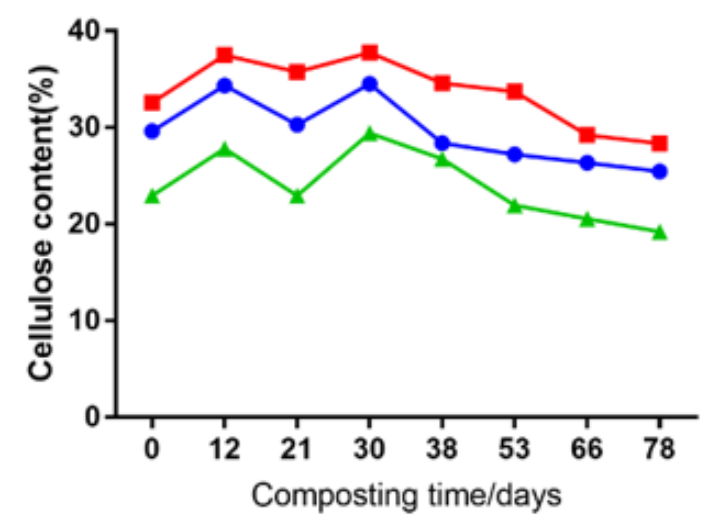

4b

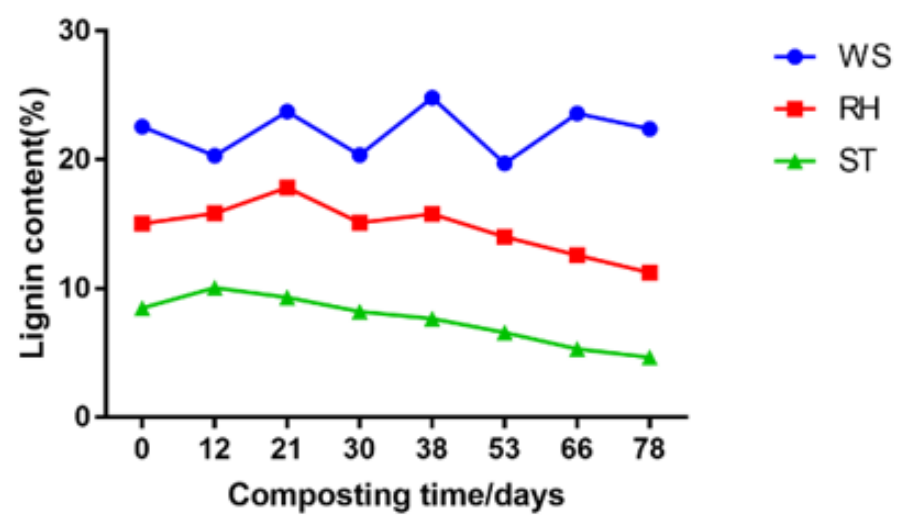

Figure 4

Variations in the cellulose and lignin content in three different treatments during the composting process. (a) cellulose content, and (b) lignin content. WS=woodchips+ swine carcasses; $\mathrm{RH}=$ rice husk +swine carcasses; $\mathrm{ST}=$ wheat straw + swine carcasses.

$5 a$

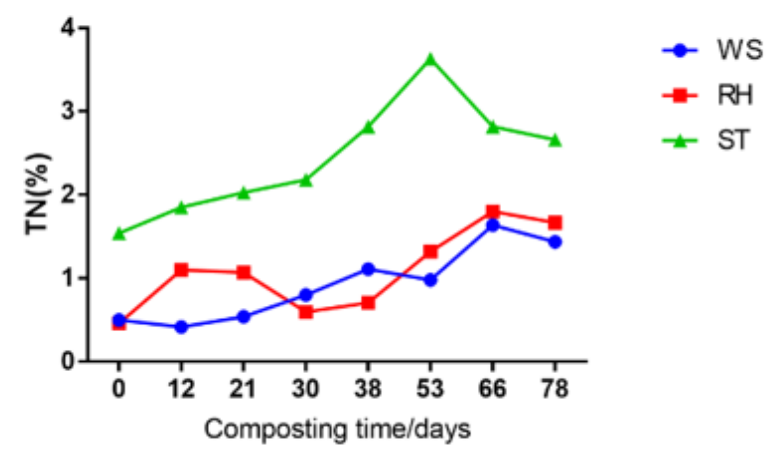

$5 b$

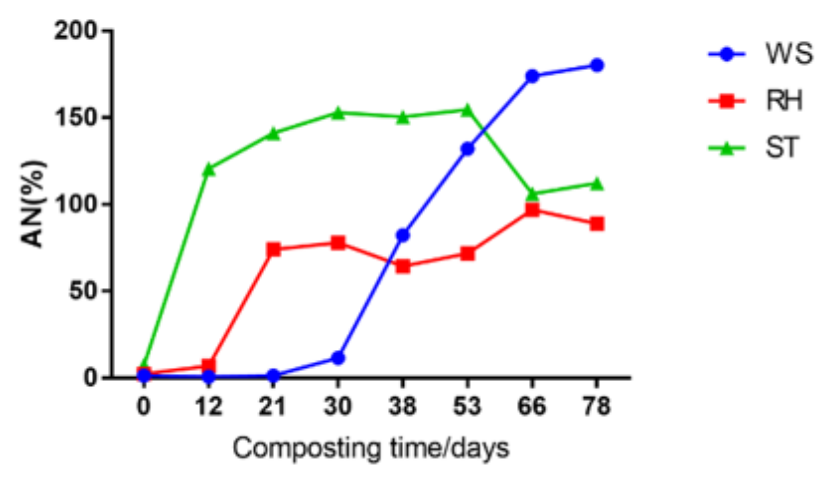

Figure 5

Variations of total nitrogen (TN) and ammonium nitrogen (AN) in three different treatments during the composting process: (a) total nitrogen content, and (b) ammonium nitrogen content. WS=woodchips + swine carcasses; $\mathrm{RH}=$ rice husk +swine carcasses; $\mathrm{ST}$ =wheat straw+ swine carcasses. 


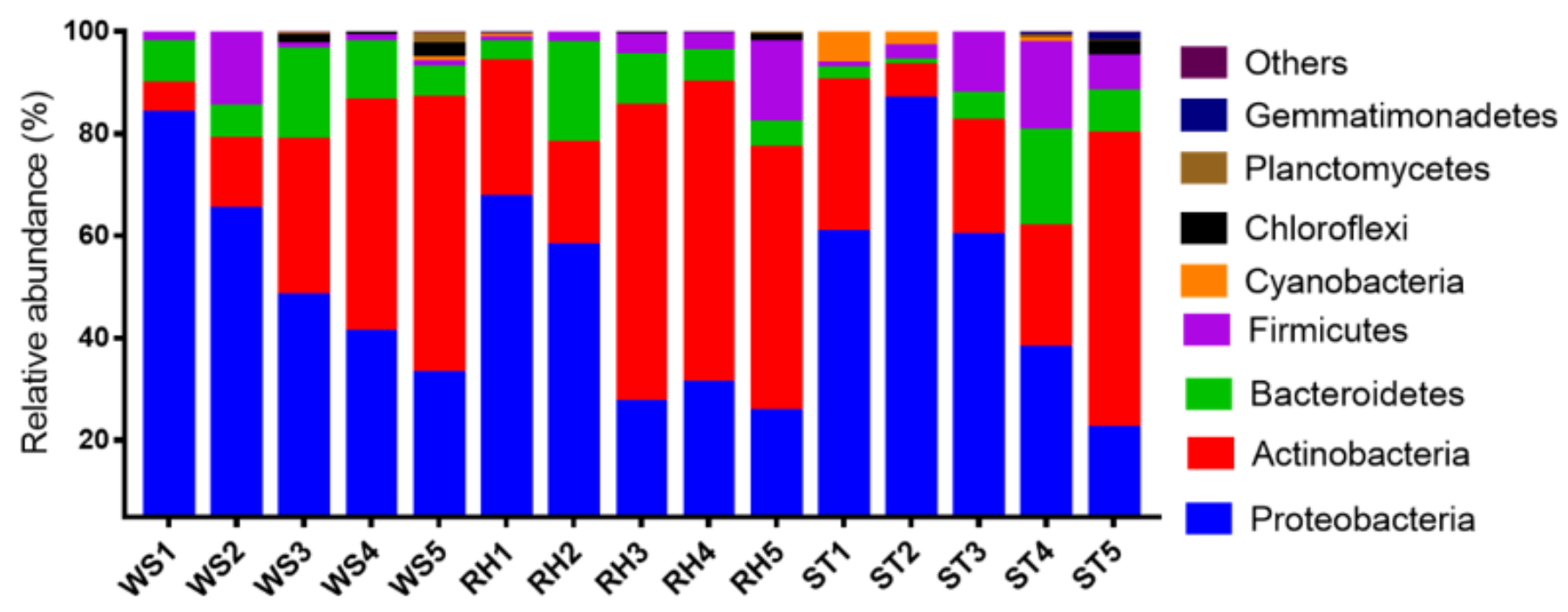

Samples

(6a)

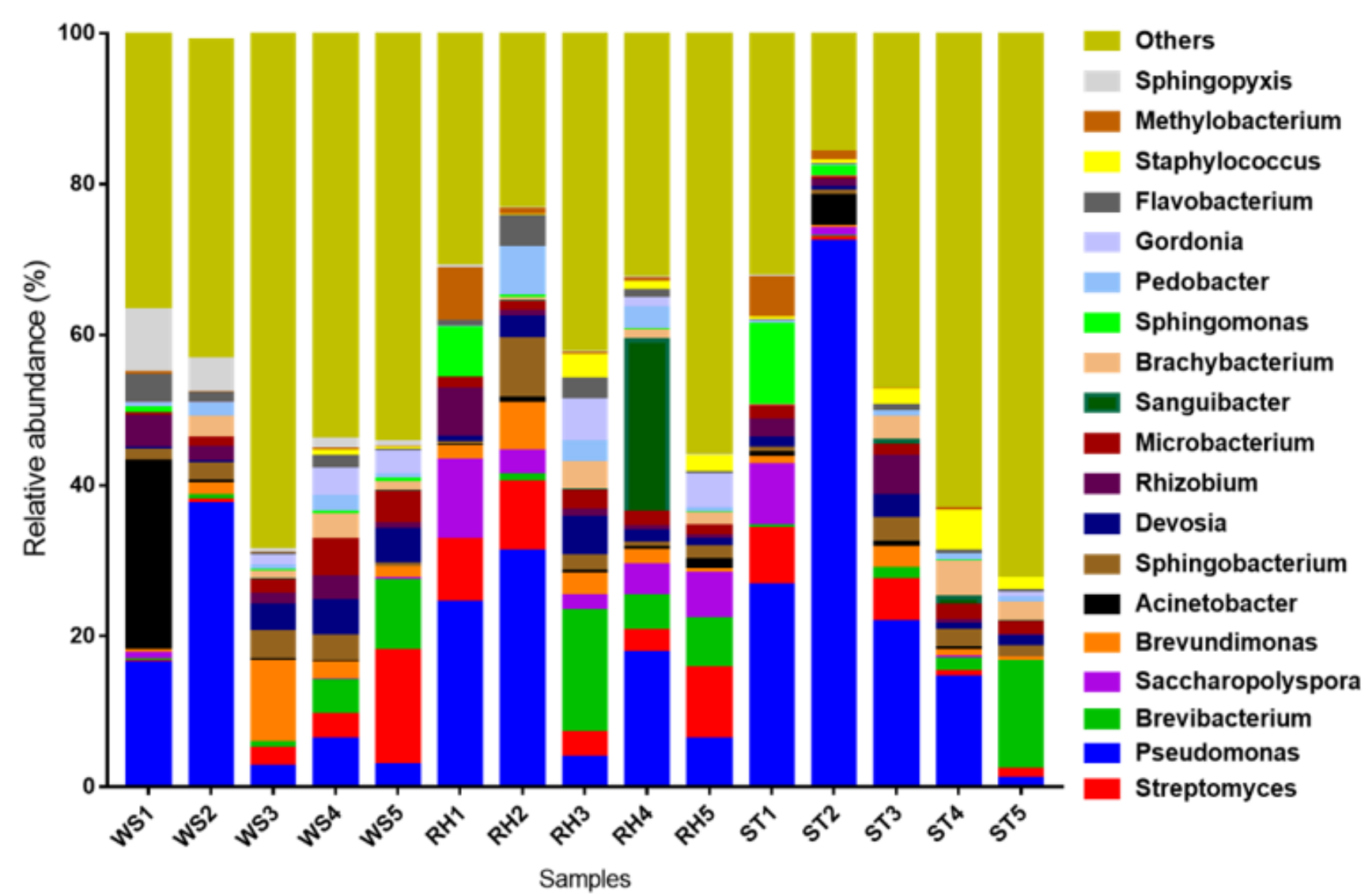

(6b)

Figure 6

Classification of 16S rRNA gene sequences at the phylum (a) and genus (b) level for each day of composting. The $x$-coordinate is arranged according to the sample name, with each column graph representing a sample and each taxon being distinguished by color. The y-coordinate represents the relative abundance of each taxon. The longer the column, the higher the relative abundance of the taxon in the corresponding sample. The samples were first clustered according to their mutual similarity, and 
then arranged horizontally according to the clustering results. Likewise, taxonomic units were also clustered according to their mutual similarity in distribution in different samples and arranged vertically according to the clustering results. In the figure, red represents the genus with higher abundance in the corresponding sample, and green represents the genus with lower abundance. WS = woodchips + swine carcasses; $\mathrm{RH}$ = rice husk + swine carcasses; $\mathrm{ST}$ = wheat straw + swine carcasses.
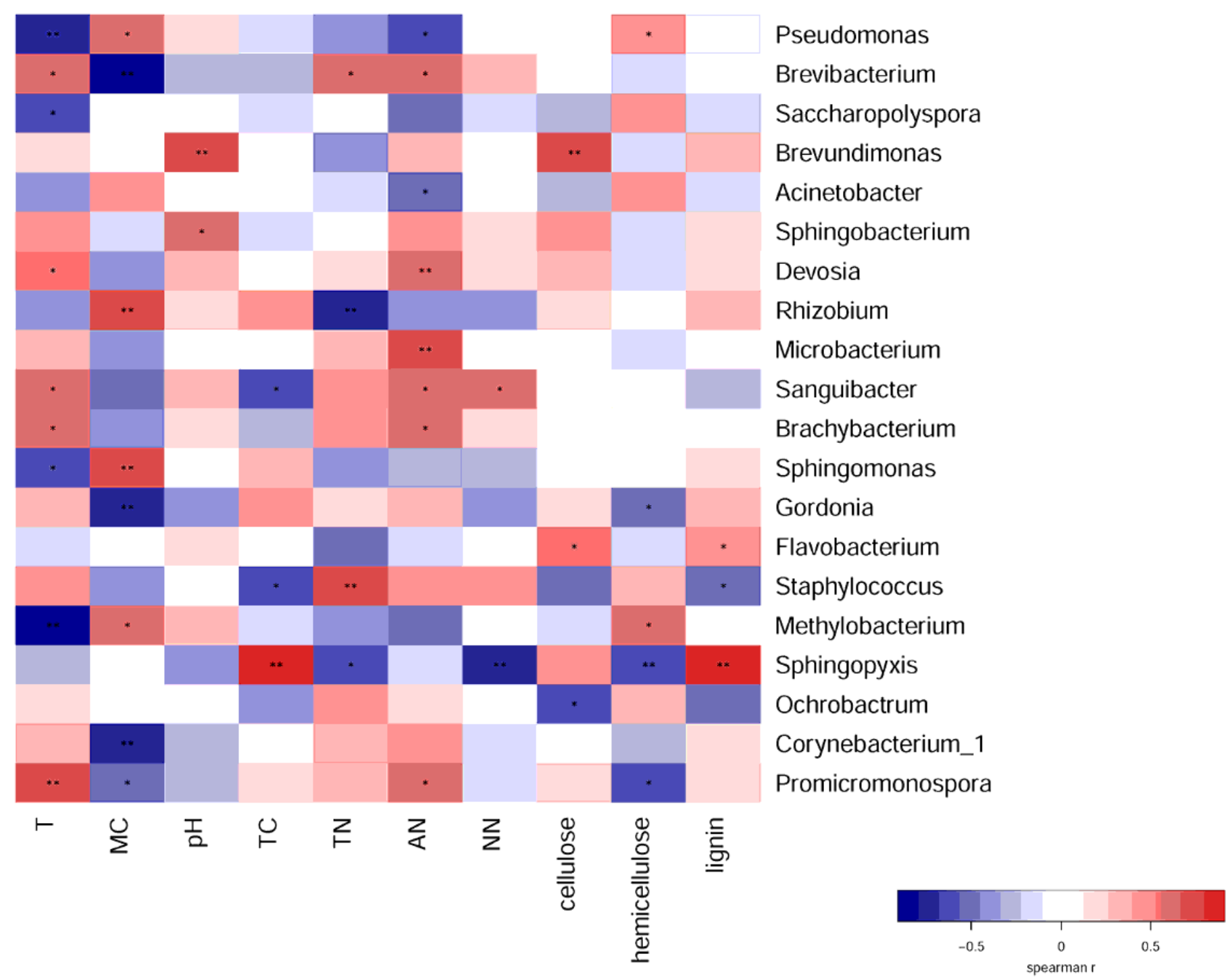

\section{Figure 7}

Spearman analysis of the relationship between environmental factors and top 20 genera. In the Spearman correlation heatmap, the $\mathrm{R}$ value is indicated by different colors, $0.01<p \leq 0.05^{\star}, 0.001<p \leq$ $0.01^{\star *}, p<0.001^{\star \star \star}$. T, temperature; MC, moisture content; TC, total organic carbon; TN, total nitrogen; NN, nitrate nitrogen.

\section{Supplementary Files}


This is a list of supplementary files associated with this preprint. Click to download.

- SupplementaryMaterial.docx 